\title{
Pediatric Vasculitis Activity Score
}

National Cancer Institute

\section{Source}

National Cancer Institute. Pediatric Vasculitis Activity Score. NCI Thesaurus. Code C121342.

A set of criteria used to determine the activity of childhood vasculitis. 